\title{
Highly bright blue organic light-emitting devices using spirobifluorene- cored conjugated compounds
}

\author{
C. C. Wu, ${ }^{\text {a) }}$ Y. T. Lin, H. H. Chiang, T. Y. Cho, and C. W. Chen \\ Department of Electrical Engineering, Graduate Institute of Electro-Optical Engineering, and Graduate \\ Institute of Electronics Engineering, National Taiwan University, Taipei, Taiwan 10617, Republic of China
}

K. T. Wong, Y. L. Liao, G. H. Lee, and S. M. Peng

Department of Chemistry, National Taiwan University, Taipei, Taiwan 10617, Republic of China

(Received 29 January 2002; accepted for publication 17 May 2002)

\begin{abstract}
An efficient and morphologically stable pyrimidine-containing spirobifluorene-cored oligoaryl, 2,7-bis[2-(4-tert-butylphenyl)pyrimidine-5-yl]-9,9' -spirobifluorene (TBPSF), as an emitter or a host for blue organic light-emitting devices (OLEDs), is reported. The steric hindrance inherent with the molecular structure renders the material a record-high neat-film photoluminescence (PL) quantum yield of $80 \%$ as a pure blue emitter (PL peak at $430 \mathrm{~nm}$ ) of low molecular weight, and a very high glass-transition temperature $\left(T_{g}\right)$ of $195^{\circ} \mathrm{C}$. Blue OLEDs employing this compound as the emitter or the emitting host exhibit unusual endurance for high currents over $5000 \mathrm{~mA} / \mathrm{cm}^{2}$. When TBPSF is used as a host for perylene in a blue OLED, maximal brightness of $\sim 80000 \mathrm{~cd} / \mathrm{m}^{2}$ had been achieved, representing the highest values reported for blue OLEDs under dc driving. (c) 2002 American Institute of Physics. [DOI: 10.1063/1.1493669]
\end{abstract}

Organic light-emitting devices (OLEDs) have been the subjects of intense investigation in recent years due to their applications in displays and lighting. ${ }^{1-3}$ In lighting applications, white-emitting devices are most desired, ${ }^{3}$ while in display applications the full-color capability is required. ${ }^{4-6}$ In all these implementations, blue-emitting materials and devices with high efficiency, good color purity, and thermal stability have been essential.

Among various blue-emitting materials reported, oligophenyls with spirobifluorene as a central linkage are prominent for simultaneously owning relatively high morphological stability and luminescence efficiency in thin films. ${ }^{3,7}$ The tetrahedral bonding at the spiro center imposes a perpendicular relationship between the two connected oligophenyl chromophores that determine the electronic and optical properties of the compound. Such a steric nonplanar structure hinders close packing and interaction between chromophores, having the molecules less subject to crystallization and luminescence quenching in thin films. However, there is still a need to further improve luminescent properties of such materials toward ideal $100 \%$ quantum yield. As an indication, spiro-sexiphenyl, a representative blue-emitting spiro compound, exhibits a photoluminescence (PL) quantum yield in solution $\left(\Phi_{\mathrm{sol}}\right)$ of $\sim 80 \%$, yet the quantum yield in thin films $\left(\Phi_{\text {film }}\right)$ drops substantially to $\sim 38 \% .^{7}$ In this letter, we report a pyrimidine-containing spirobifluorenecored oligoaryl, 2,7-bis[2-(4-tert-butylphenyl)pyrimidine5-yl]-9, $9^{\prime}$-spirobifluorene (TBPSF), which has a very high $T_{g}$ and is able to preserve a very high PL quantum yield in thin films. It is also shown that blue OLEDs employing this compound as the emitting host can sustain a high current density over $5000 \mathrm{~mA} / \mathrm{cm}^{2}$, giving very high brightness under dc driving.

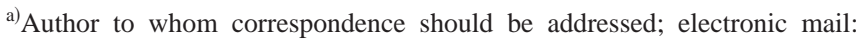
chungwu@cc.ee.ntu.edu.tw
}

Figure 1(a) shows the chemical structure of TBPSF, mainly containing a pyrimidine-containing hexaaryl linked perpendicularly with biphenyl through a spiro center [Fig. 1(b)]. TBPSF was synthesized through the Suzuki coupling reaction of 2,7-diboronic ester of 9,9' $9^{\prime}$-spirobifluorene and 5-bromo-2-(4-tert-butylphenyl)-pyrimidine in the presence of $\mathrm{Pd}\left(\mathrm{PPh}_{3}\right)_{4}$ and $\mathrm{P}^{t} \mathrm{Bu}_{3}$ catalysts with high yield $(94 \%) .{ }^{8-10}$ Further details of synthesis and chemical analysis of TBPSF will be reported elsewhere. Figure 1(b) shows molecular structure of TBPSF derived from x-ray diffraction analysis of its single crystal. The main hexaaryl backbone, which dominates the electronic and optical properties of interest, has a boomerang shape induced by the rigid fluorene moiety and has rigid bulky $t$-butyl groups at both ends. The cross-shaped spirobifluorene moiety and the $t$-butyls are introduced to provide the steric hindrance to packing and interaction of hexaaryl chromophores. The introduction of the electronaccepting pyrimidine moiety is expected to provide the molecule with a relatively large electron affinity (EA). ${ }^{10}$ This has been confirmed by its estimated EA of $\sim 3 \mathrm{eV}$ in thin films, obtained by subtracting the optical energy gap of $3.02 \mathrm{eV}$ (estimated from the absorption onset, Fig. 2) from its measured thin-film ionization potential $\left(I_{p}\right)$ of $\sim 6.1 \mathrm{eV} .{ }^{11}$ Such

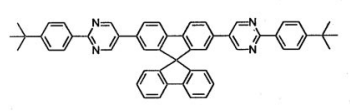

(a) TBPSF

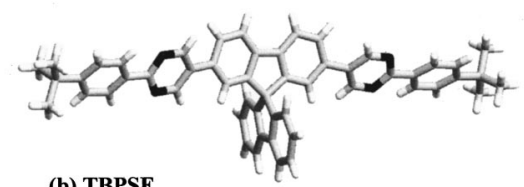

(b) TBPSF

FIG. 1. (a) Chemical structure of TBPSF. (b) X-ray molecular structure of TBPSF. (c) Chemical structure of NCB. 


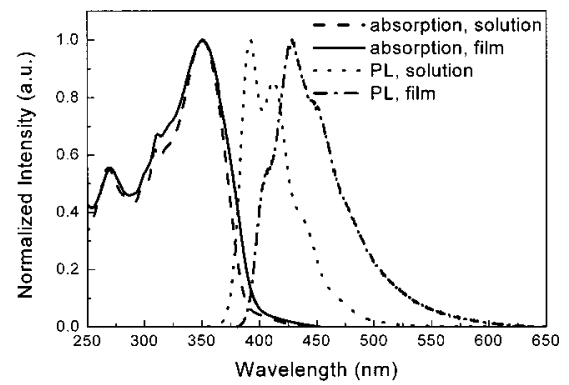

FIG. 2. Absorption and PL spectra of TBPSF in solution $\left(\mathrm{CHCl}_{3}, 5\right.$ $\left.\times 10^{-6} \mathrm{M}\right)$ and in thin film.

an EA value is comparable to that of the typical electrontransport material tris(8-hydroxyquinoline)aluminum $\left(\mathrm{Alq}_{3}\right) .{ }^{11} \mathrm{~A}$ further consequence of pyrimidine moieties is the improvement of planarity of the hexaaryl chromophore in comparison with pure phenyl systems. In $p$-oligophenyls, ortho-ortho interaction results into twists between neighboring phenyl rings, ${ }^{12,13}$ while in TBPSF, pyrimidines and the terminal phenyl rings assume a coplanar configuration due to the lack of hydrogen atoms connected to nitrogen atoms of pyrimidine and therefore the lack of ortho-ortho interaction.

Thermal analysis of TBPSF reveals its high thermal stability. The decomposition temperature of TBPSF, corresponding to $5 \%$ weight loss upon heating in thermogravimetric analysis, is around $420^{\circ} \mathrm{C}$. The differential scanning calorimetry of TBPSF exhibits a distinct glass transition around $195^{\circ} \mathrm{C}$. As a consequence, TBPSF is able to form homogeneous and stable amorphous films by thermal evaporation, a basic requirement for materials to be used as hosts in OLEDs. These results indicate that linking two symmetrical oligoaryl branches through the spiro center might not be a necessity to obtain high $T_{g}$ and that the nonsymmetrical one-branch system is equally effective. The reduced molecular weight of one-branch structures may be beneficial to subsequent preparation and processing of materials.

Figure 2 shows the optical spectra of TBPSF in solution and in thin films. The nearly identical absorption spectra in solution and in films suggest that there is minimal intermolecular interaction in the ground state in thin films. PL of both solution and thin films exhibit pure blue emission and corresponding vibronic features, although there is a difference in relative peak intensities and a shift of $10-15 \mathrm{~nm}$ in peak positions. These differences may be caused by the different dielectric environments surrounding molecules. ${ }^{7}$

TBPSF exhibits very high PL quantum yields both in solution and in thin films. $\Phi_{\text {sol }}$ of TBPSF was determined using standard procedures with blue dye coumarin 1 as in Ref. 14. $\Phi_{\text {film }}$ of TBPSF was determined using a calibrated integrating sphere system. ${ }^{15}$ In our integrating sphere system, $\Phi_{\text {film }}$ of the typical green OLED material, $\mathrm{Alq}_{3}$ was determined to be $25 \pm 3 \%$, consistent with previously reported values. ${ }^{16,17}$ The thus determined $\Phi_{\text {sol }}\left(\right.$ in $\left.\mathrm{CHCl}_{3}\right)$ and $\Phi_{\text {film }}$ of TBPSF are near $100 \%$ and $80 \%$, respectively. It is noteworthy that both values are substantially higher than those of spiro-oligophenyl analogues. In particular, $\Phi_{\text {film }}$ of $80 \%$ is unusually high and represents the highest value ever reported for a pure blue emitter of small molecular weight in neat films.

The enhancement of the PL quantum yield for TBPSF molecules in comparison with the spiro-oligophenyls is attributed to improved planarity of the chromophore in the ground state. In oligoaryls, the aryl rings are usually connected in a more planar configuration in the excited state. ${ }^{12,13}$ When the planarity in the ground state is improved to better match the conformation of the excited state, the intensity of the transition is generally increased, along with enhanced emission efficiency. ${ }^{12,13}$ On the other hand, the steric hindrance inherent with the molecular structure surely plays the major role in preservation of the high quantum yield in thin films. With only one chromophore branch on the spiro linkage, the probability of direct and extended alignment between oligoaryl chromophores (and consequent quenching) is probably also reduced as compared with two-branch systems.

To study electroluminescent (EL) properties of highly efficient TBPSF, multilayer devices with the configuration of glass/indium-tin-oxide anode/hole-injection layer (HIL)/ hole-transport layer (HTL)/emitting layer (EML)/electron transport layer (ETL)/electron-injection layer (EIL)/Al cathode were fabricated. A thin layer of conducting polymer polyethylene dioxythiophene/polystyrene sulphonate (PEDT/ PSS, Bayer Corp.) was used as a HIL, ${ }^{18} 4$-(N-carbazolyl)$4^{\prime}$-(N-phenylnapthylamino)biphenyl [(NCB) Fig. 1(c)] as a $\mathrm{HTL},{ }^{19} \mathrm{Alq}_{3}$ as an ETL, ${ }^{1}$ and TBPSF (nondoped or doped) as EML. $5 \AA \mathrm{LiF}$ was used as EIL. ${ }^{20}$ All the organic compounds of low molecular weight were purified by vacuum sublimation before use. PEDT/PSS was deposited by spincoating and all other materials were deposited by vacuum deposition. The thicknesses of PEDT/PSS, NCB, TBPSF, and $\mathrm{Alq}_{3}$ were $\sim 30,45,30$, and $20 \mathrm{~nm}$, respectively. The current-voltagebrightness $(I-V-L)$ characteristics of devices were measured using an Agilent 4155B semiconductor parameter analyzer and a $\mathrm{Si}$ photodiode calibrated with Photo Research PR-650 spectroradiometer.

Initial experiments on devices using the typical $\alpha$-naphthylphenylbiphenyl diamine ( $\alpha$-NPD) as HTL $^{21}$ gave low EL efficiency and substantially redshifted emission relative to TBPSF emission. It is presumably due to large barrier for holes and the formation of exciplexes at the interface of TBPSF and the low- $I_{p} \alpha$-NPD $\left(I_{p} \sim 5.4 \mathrm{eV}\right) .{ }^{22}$ Using NCB with a higher $I_{p}(\sim 5.8 \mathrm{eV})$, better matching that of TBPSF, removed the exciplex problem and enhanced hole injection into TBPSF, largely improving EL efficiency. Furthermore, NCB has a substantially higher $T_{g}$ than $\alpha$-NPD. ${ }^{19}$ Since TBPSF has a relatively large EA suitable for electron injection, initially devices without $\mathrm{Alq}_{3}$ were also fabricated. The EL efficiency of such devices is similar to that of devices with $\mathrm{Alq}_{3}$, however, with a substantially higher operation voltage. It suggests that TBPSF be a poorer electron transporter than $\mathrm{Alq}_{3}$, so that eventually $\mathrm{Alq}_{3}$ was added in the device structure as ETL.

The nondoped device shows pure blue EL [Fig. 3(a)] from TBPSF. In doping TBPSF with 1 wt. $\%$ blue-emitting perylene, the EL completely converted into that of perylene, indicating very efficient resonant energy transfer from TBPSF to perylene. $I-V-L$ characteristics of both devices are shown in Figs. 3(b) and 3(c). Both devices exhibit unusual endurance for high currents. Injection current over $5000 \mathrm{~mA} / \mathrm{cm}^{2}$ had been achieved, giving maximal bright- 
(a)

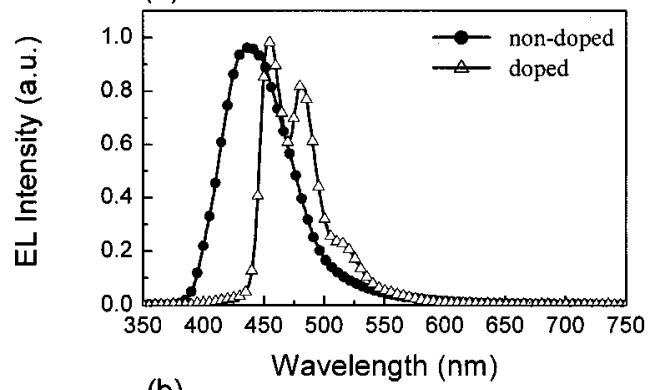

(b)

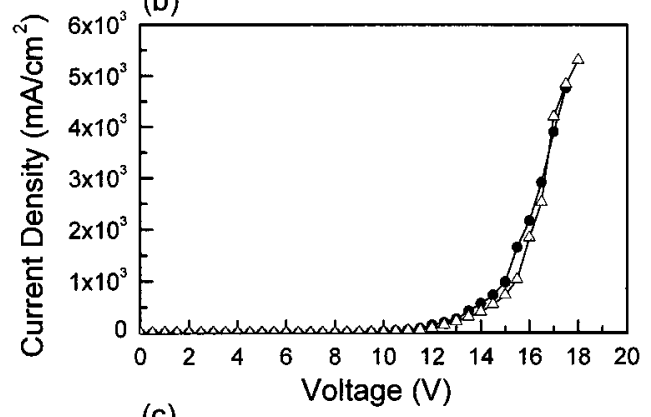

(c)

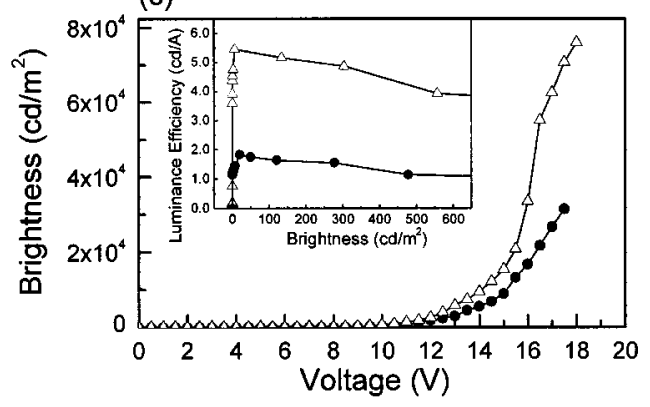

FIG. 3. (a) EL spectra, (b) $I-V$ characteristics and (c) $L-V$ characteristics of nondoped and perylene-doped devices. Device structure: ITO/PEDT:PSS $(\sim 30 \mathrm{~nm}) / \mathrm{NCB}(45 \mathrm{~nm}) / \mathrm{TBPSF}$ or TBPSF:perylene $(30 \mathrm{~nm}) / \mathrm{Alq}_{3}(20 \mathrm{~nm})$ $\mathrm{LiF}(0.5 \mathrm{~nm}) / \mathrm{Al}$. Device area: $1 \mathrm{~mm} \times 1 \mathrm{~mm}$. Inset of (c): EL efficiencies for both devices.

ness' of $>30000 \mathrm{~cd} / \mathrm{m}^{2}$ and $\sim 80000 \mathrm{~cd} / \mathrm{m}^{2}$ for nondoped and doped devices, respectively. Such high current endurance is ascribed to the high $T_{g}$ of the active layers used, rendering the device more resistant against joul heating. Although high brightness levels of $\sim 50000 \mathrm{~cd} / \mathrm{m}^{2}$ have been reported for blue small-molecule OLEDs under pulsed operation with extremely small duty ratios, ${ }^{5,23}$ the brightness value of $\sim 80000 \mathrm{~cd} / \mathrm{m}^{2}$ achieved here by the perylene-doped TBPSF device represents the highest value ever reported for dc driving.

The EL efficiencies of devices at $100 \mathrm{~cd} / \mathrm{m}^{2}$ are about $2.3 \%$ photon/electron $(1.6 \mathrm{~cd} / \mathrm{A})$ and $4 \%(5.2 \mathrm{~cd} / \mathrm{A})$ for nondoped and doped devices, respectively [inset of Fig. 3(c)]. The $2.3 \%$ efficiency of the nondoped device is relatively high for a pure blue emitter. Nevertheless, it is lower than one can expect from very high $\Phi_{\text {film }}$ of TBPSF, assuming balanced hole/electron injection and transport. Furthermore, the turn-on voltage (defined as the voltage at which device emission becomes detectable) is as high as $\sim 4 \mathrm{~V}$. These are most probably due to poorer hole injection from anode, resulting from the high- $I_{p}$ materials involved in the present device. Full utilization of high $\Phi_{\text {film }}$ for device efficiency may rely on further improving the hole injection/hole transport by using multiple HTLs or by tuning energy levels of the blue-emitting compound. Already the observed efficiency enhancement with doping may be due to the retardation of electron transport through trapping on perylene dopants. This is indeed consistent with our electrochemical characterization of TBPSF and perylene, in which perylene shows a $0.1-$ $0.2 \mathrm{~V}$ smaller reduction potential (and therefore lower-lying lowest unoccupied molecular orbital level) than TBPSF.

In conclusion, we have shown that by carefully designing molecular structures, materials based on oligoaryls can provide very high thermal stability and neat-film PL quantum yield for pure blue emission. It is also shown that such compounds can be used to fabricate efficient blue OLEDs. Currently, further work is toward the optimization of materials and devices to achieve lower voltage and higher power efficiency, and toward the investigation of operational stability of devices employing such class of materials.

The authors would like to thank AU Optronics for assistance in $I_{p}$ measurements. This work was supported in part by National Science Council (Grant Nos. NSC 90-2215-E002-025 and NSC 90-2113-M-002-044) and Ministry of Education of the Republic of China.

${ }^{1}$ C. W. Tang and S. A. VanSlyke, Appl. Phys. Lett. 51, 913 (1987).

${ }^{2}$ C. W. Tang, S. A. VanSlyke, and C. H. Chen, J. Appl. Phys. 65, 3610 (1989).

${ }^{3}$ F. Steuber, J. Staudigel, M. Stössel, J. Simmerer, A. Winnacker, H. Spreitzer, F. Weissörtel, and J. Salbeck, Adv. Mater. 12, 130 (2000).

${ }^{4}$ S. Miyaguchi, S. Ishizuka, T. Wakimoto, J. Funaki, Y. Fukuda, H. Kubota, K. Yoshida, T. Watanabe, H. Ochi, T. Sakamoto, M. Tsuchida, I. Oshita, and T. Tohma, Extended Abstracts, Proceedings of the Ninth International Workshop on Inorganic and Organic Electroluminescence, Bend, OR, 1998, p. 137.

${ }^{5}$ C. Hosokawa, Synth. Met. 91, 3 (1997).

${ }^{6}$ J. Kido, M. Kimura, and K. Nagai, Science 267, 1332 (1995).

${ }^{7}$ J. Salbeck, N. Yu, J. Bauer, F. Weissörtel, and H. Bestgen, Synth. Met. 91, 209 (1997).

${ }^{8}$ K.-T. Wong, T. S. Hung, Y.-T. Lin, C.-C. Wu, G.-H. Lee, S.-M. Peng, C. H. Chou, and Y. O. Su, Org. Lett. (to be published).

${ }^{9}$ W.-L. Yu, J. Pei, W. Huang, and A. J. Heeger, Adv. Mater. 12, 828 (2000).

${ }^{10}$ R. Gommper, H.-J. Mair, and K. Polborn, Synthesis , 696 (1997); J. W. Goodby, M. Hird, R. A. Lewis, and K. J. Toyne, Chem. Commun. (Cambridge), 2179 (1996).

${ }^{11}$ (a) $I_{p}$ was measured with a low-energy photoelectron spectrometer RikenKeiki AC-2; (b) T. Sano, Y. Hamada, and K. Shibata, IEEE J. Sel. Top. Quantum Electron. 4, 34 (1998).

${ }^{12}$ J. M. Kauffman, P. T. Litak, J. A. Novinski, C. J. Kelley, A. Ghiorghis, and Y. J. Qin, J. Fluoresc. 5, 295 (1995).

${ }^{13}$ J. B. Birks, Photophysics of Aromatic Molecules (Wiley, New York, 1970).

${ }^{14}$ G. Jones II, W. R. Jackson, C. Y. Choi, and W. R. Bergmark, J. Phys. Chem. 89, 294 (1985).

${ }^{15}$ J. C. de Mello, H. F. Wittmann, and R. H. Friend, Adv. Mater. 9, 230 (1997); The $325 \mathrm{~nm}$ line of the $\mathrm{He}-\mathrm{Cd}$ laser was used to excite samples placed in a calibrated integrating sphere that was coupled with a cooled charge coupled device spectragraph and was purged with dry nitrogen, following procedures previously reported in (a).

${ }^{16}$ H. Mattoussi, H. Murata, C. D. Merritt, Y. Iizumi, J. Kido, and A. H. Kafafi, J. Appl. Phys. 86, 2642 (1999).

${ }^{17}$ D. Z. Garbuzov, S. R. Forrest, A. G. Tsekoun, V. Bulovic, and M. E. Thompson, J. Appl. Phys. 80, 4644 (1996).

${ }^{18}$ A. Elschner, F. Bruder, H-W. Heuer, F. Jonas, A. Karbach, S. Kirchmeyer, S. Thurm, and R. Wehrmann, Synth. Met. 111, 139 (2000).

${ }^{19}$ D. F. O'Brien, P. E. Burrows, S. R. Forrest, B. E. Koene, D. E. Loy, and M. E. Thompson, Adv. Mater. 10, 1108 (1998).

${ }^{20}$ L. S. Hung, C. W. Tang, and M. G. Mason, Appl. Phys. Lett. 70, 152 (1997).

${ }^{21}$ J. Shi and C. W. Tang, Appl. Phys. Lett. 70, 1665 (1997).

${ }^{22}$ N. Tamoto, C. Adachi, and K. Nagai, Chem. Mater. 9, 1077 (1997).

${ }^{23}$ Y. Kijima, N. Asai, and S. Tamura, Jpn. J. Appl. Phys., Part 1 38, 5247 (1999). 
Applied Physics Letters is copyrighted by the American Institute of Physics (AIP). Redistribution of journal material is subject to the AIP online journal license and/or AIP copyright. For more information, see http:/ojps.aip.org/aplo/aplcr.jsp

Copyright of Applied Physics Letters is the property of American Institute of Physics and its content may not be copied or emailed to multiple sites or posted to a listserv without the copyright holder's express written permission. However, users may print, download, or email articles for individual use. 